\title{
Present Situation and Improved Measures of Medical Equipment
}

\author{
Hongjie Gao \\ People's Hospital of Zhengzhou, \\ Zhengzhou City, P.R. China \\ E-mail: tuke126@126.com
}

\begin{abstract}
Keywords: maintenance management, perfect rules and regulations, classification maintenance.
\end{abstract}
\begin{abstract}
With the rapid development of medical and health undertakings in China, the requirement of the qualified medical service system was increasing, more and more medical had introduced the advanced medical equipment, the introduction of a large number of equipment to make the medical equipment maintenance management face new challenges. This paper analyzed the present existing problems of hospital medical equipment maintenance management and production, and elaborated that the modern hospital medical equipment maintenance management should enhance the technical levels of staff. There were four aspects to ensure the quality of medical equipment maintenance, such as equipped complete maintenance equipment, established complete regulations, strict control equipment purchase source qualified guarantee of after-sales service and carry out gradation administration of maintenance pattern.
\end{abstract}

\section{Introduction}

\section{The Increasing Medical Equipment Technology Level.}

On behalf of the forefront of high-tech medical equipment, integrating multiple disciplines, Many inventions of medical device were first used in military and medical care. CT equipment was a revolution of the application of X-ray and combined with X-ray, computer, electronic computer image and MR. And MR was the achievement of electromagnetism and computer. LA was the combination of the microwave technology in the field of military and computer, X-knife almost integrated all camera equipment, such as CT, MR, LA and TPS. In addition, there were many different kinds of medical equipment.almost each organs had its corresponding function testing equipment, which developed tend to be more functional, volume miniaturization shorter update cycle[1].

\section{Relatively Insufficient Maintenance Personnel.}

At present, although the medical engineering technical personnel's knowledge and technical level had significantly improved than decades back, due to many reasons, the medical engineering technical personnel's maintenance ability could not be with medical sale of synchronous update rate. Medical engineering science in China started late, and and the corresponding medical engineering science education had many malpractice. The occupied professional knowledge was mostly classical theory of medical engineering, and involving few theory and technology. During the study in campus, the extremely lack of practice resulted in these highly educated talents could not perform proper rule after entering the hospital. Is domestic hospital, the importance of medical equipment maintenance personnel was lower evaluated, and with negligence of management. These staff more or less could face unfair treatment in the evaluation of job promotion and academic research, which could hinder the improvements of knowledge and skills of maintenance personnel, inactivated their work enthusiasm, and caused the outflow of talents[2].

\section{Incomplete Detection Device and Lagged behind Maintenance.}

The testing maintenance tools of the domestic hospital for medical equipment maintenance personnel was very simple, some time its a multimeter. In today's high-tech development, the imported high and refined medical equipment had high level of electronic, automation, integration and computerization degree. The simple multimeter and oscillograph was difficult to carry out medical device testing work[3]. Especially, some of the imported large equipment were lack of 
circuit diagram, maintenance and technical instruction. If these equipment malfunction, there was no much more to do.

\section{Secondary Monopoly of Medical Equipment after-sale Becoming more Serious.}

After-sales service should be the commodity marketing for brand maintenance, customers service and market expansion. The market should be maintained to ensure its stable status, as it was a kind of recessive service, also the embodiment of the business reputation and integrity. But at present a lot of medical equipment suppliers often provide incomplete or did not provide maintenance tools, special tools, circuit diagram and the necessary technical data, such as the maintenance password, caused the hospital not be able to equipment maintenance personnel for maintenance, such as maintenance password set, special fastening device and gave the line drawings, unclear marking, omitted information, false drawings, malicious altered annotations on the polished components, made the hospital medical engineering staff cannot normal maintenance on equipment. Due to its particularity, medical equipment maintenance technology monopoly made after-sales service gradually evolved into a industrial chain. Many foreign companies promoted after-sales service during the trade, namely "buy warranty". Although under the service quality improvement and all for customer, the hidden behind huge profit was significant. Apart from the profits in sales, the after-sales service could also offer huge profits, the producer and supplier had formed the situation of always win situation.

\section{Improvement Measures}

\section{Enhancing the Personnel Technical Level, Equipped with Complete Equipment Maintenance.}

As the carrier and tool of the service from medical staff, medical equipment had the characteristics of high technology content and complex structure. Only qualified personnel could engage in the maintenance work. Foreign hospital service agencies management rules was followed to establish system of maintenance personnel access. A specially trained and assessment of the qualified personnel engaged in maintenance work accordingly. The personnel without qualifications should be forbidden to work in hospital medical equipment maintenance. There were many methods to improve staff technical level, such as short-term training, further study, regular specific lectures, discuss on problems and exchange experiences with each other. Advanced medical equipment in modern hospital basically had electronization, automation and computerization. The multimeter and oscillogragh was difficult to work. Hospitals must be equipped with modern testing maintenance equipment for maintenance personnel, such as equipped with T4040 online meter test equipment. The maintenance personnel could be online detection of fault in the plate, repair rate could reach $80 \%$ and lower cost.

\section{Establish Complete Rules and Regulations to Strengthen the Management.}

To build a high qualified equipment maintenance engineering team, the management of the maintenance personnel should be enhanced to strengthen the management. Maintenance personnel must establish and perfect rules and regulations. According to existing personnel's actual work ability, it could be divided into image equipment group, biochemistry group, medical appliance group, computer network equipment group, and other professional maintenance team. In this way, the responsibility of personnel, clear division of responsibility, the division of labor and machinery, division of labor and cooperation, establish the collective idea of maintenance, to ensure the quality of efficient and orderly, meet the clinical requirement. Establish equipment maintenance records, accumulate information, with the usual maintenance records for maintenance experience. After the maintenance work, it need a timely summary, a good job notes, the change of parts and components, lines or piping detailed records for later check. From the equipment patrol system, the usage of each department medical equipment, problem and clinical requirements could be timely discovered and solved some fault and trouble. The engineer performance in charge of the hospital medical equipment first deal with the problem. Hospital engineers in charge of the entire system, that is, all maintenance work shall be carried out under the condition of the hospital in charge of the engineer involved in. 
Guarantee of the Quality of After-sales Service from the Equipment Purchase Source.

In the process of equipment bidding, the tender documents must include telephone equipment after-sales service commitment[5,6]. Two years of free warranty period. Above $95 \%$ of operation rate in each year during the three years. The response time should be 4 hours, arrival time should be within 8 hours for local place, 24 hours for other place. The repair time should be 48 hours, within warranty, exceed 48 hours, and still did not repaired well, the compensation should be paid according to the user average daily workload. Free updated for software. Technological equipment was supplied at the $80 \%$ of the market price. The main parts price of the equipment should be set. For supplier who unable provide complete data, it need extend the equipment free warranty as the compensation. In addition, equipment suppliers should provide a complete random data to the hospital. The detailed Chinese operating instructions should be offered along with maintenance manuals, including electronic circuit diagram, detailed contend and daily maintenance methods and common problem of discharge method, software maintenance and servicing password, technical parameters of the equipment information. Equipment suppliers should provide equipment operation training for the hospital staff. The engineer of hospital equipment should receive maintenance training to make the engineers to equipment basic principle. The function of the main components, the content and method of daily maintenance and malfunction education and maintenance for learning in order to deal with common problem.

Maintenance Classification Mode to Ensure the Quality of Maintenance.

In the implementation of medical equipment, many health care institution at home and abroad had taken initiative preventive maintenance, repair and maintenance afterwards combining the classification of maintenance mode[7], which had achieved significant results, and made the repair work be carried out in an orderly way. Particularly, large medical equipment followed the preventive maintenance, such as DSA, CT, MRI, X-knife radiosurgery, linear accelerator. Medium-sized medical equipment should have the combination of preventative maintenance and initiative maintenance, such as fiber microscopy, ultraviolet spectrophotometer, automatic analyzer, etc. Small medical equipment should follow the destined maintenance, such as fiber microscopy, ultraviolet spectrophotometer, automatic analyzer, etc. The proactive maintenance mode should be applied on small medical equipment, such as electrocardiogram machine. In addition, no matter large, medium or small medical equipment, regular maintenance was very important. It could prolong the service life of equipment, and reduced the number of maintenance in order to improve the economic benefit.

\section{Conclusion}

Medical institutions should attach great importance to the construction of equipment maintenance department, strength the cultivation of the equipment maintenance and technical personnel. Medical equipment maintenance personnel should have the right attitude for the work. In order to ensure the normal operation of medical instrument and equipment and dedication, and change the old tradition improper concept. A soldering iron, a screwdriver and a multimeter were unable to fit the maintenance. It need to establish the scientific management and maintenance of the idea, constantly improve their own knowledge. At the same time, hospital should further improve the system of medical equipment after-sales service and maintenance specification, better improve the quality of medical equipment after-sales service, promoted the harmonious development of medical and health undertakings.

\section{References}

[1] G. P. LI, Analysis of the specification for medical equipment maintenance management model. Information of Medical Equipment, 2003,18(3):59-60.

[2] F. R. WANG, The first time to explore the problems and countermeasures of the maintenance of medical equipment[J]. Information of Medical Equipment,2004,20(1):56-58. 
[3] Y. B. ZHONG, The difficults and development path of maintenance of large-scale precision smart imported medical equipment[J]. China Medical Device Information,1996,2(3):40-41.

[4] D. H. KANG, H. X. FANG, Q. R. TONG. Analysis and discussion of after-sales service of medical equipment[J]. Chinese Medical Equipment Journal,2008,9(4):80-81.

[5] J. Z. ZHANG, X. M. LOU, L. YE, Discussion the problems and solutions of the after-sales service of medical equipment[J].Chinese Medical Devices, 2010, 25(8):79-80.

[6] J. S. MENG JS. Specialization, Co-operative, the solutions of after-sales service of medical equipment[J].Medical Health-care Appratus, 2007,14(6):62-63.

[7] Q. L. SHI, The maintenance management and technical support of medical equipment[J]. Chinese Medical Equipment Journal,1994,(1):28-30. 